\title{
INFLUÊNCIA DE ROTAÇÕES DE CULTURAS NAS PROPRIEDADES FÍSICO- HÍDRICAS DE UM LATOSSOLO VERMELHO EM PLANTIO DIRETO ${ }^{1}$
}

\author{
EURÂIMI DE Q. CUNHA ${ }^{2}$, LUIZ C. BALBINO ${ }^{3}$, LUÍS F. STONE ${ }^{3}$, \\ WILSON M. LEANDRO ${ }^{4}$, GERALDO C. DE OLIVEIRA ${ }^{4}$
}

\begin{abstract}
RESUMO: A adoção do plantio direto, com a inclusão de espécies gramíneas de relação $\mathrm{C} / \mathrm{N}$ alta, poderá minimizar a degradação estrutural do solo. O objetivo deste trabalho foi avaliar a influência da inclusão da braquiária na rotação de culturas nas propriedades físico-hídricas e no conteúdo de matéria orgânica de um Latossolo Vermelho distrófico em plantio direto. O delineamento experimental foi o de blocos ao acaso, em parcelas subdivididas, com quatro repetições. As parcelas foram compostas por quatro sistemas de rotação, e as subparcelas, por quatro profundidades de amostragem $(0-10 ; 10-20 ; 20-40$, e $40-60 \mathrm{~cm})$. As culturas utilizadas foram: arroz (A); feijão irrigado (F); milho (M); soja (S), e arroz (A+B), milho (M+B) e soja (S+B) consorciados com braquiária. Os sistemas de rotação foram: $S 1$ - A/F/M/F/S/F; S2 $\mathrm{A}+\mathrm{B} / \mathrm{F} / \mathrm{M}+\mathrm{B} / \mathrm{F} / \mathrm{S}+\mathrm{B} / \mathrm{F} ; \mathrm{S} 3-\mathrm{M} / \mathrm{F} / \mathrm{S} / \mathrm{F} / \mathrm{S} / \mathrm{F}$, e $\mathrm{S} 4-\mathrm{M}+\mathrm{B} / \mathrm{F} / \mathrm{S}+\mathrm{B} / \mathrm{F} / \mathrm{S}+\mathrm{B} / \mathrm{F}$. Uma área de mata nativa, situada a $500 \mathrm{~m}$ do experimento, foi considerada como controle. A inclusão da braquiária na rotação de culturas não afetou a densidade, a macroporosidade e a capacidade de água disponível do solo. A porosidade total e o teor de matéria orgânica do solo foram favorecidos pelas rotações que incluíam maior número de cultivos de soja. A associação de soja com a braquiária contribuiu para a estabilidade dos agregados, e a de gramíneas de verão com a braquiária, para a diminuição da resistência do solo à penetração.
\end{abstract}

PALAVRAS-CHAVE: densidade do solo, porosidade do solo, agregação do solo.

\section{INFLUENCE OF CROP ROTATIONS ON THE PHYSICAL-HYDRICAL PROPERTIES OF AN OXISOL IN NO-TILLAGE SYSTEM}

\begin{abstract}
The adoption of no-tillage system, with the inclusion of grass species of high $\mathrm{C} / \mathrm{N}$ relationship, can minimize the structural degradation of the soil. The objective of this research was to evaluate the influence of including Brachiaria in crop rotation systems on the physical-hydric properties and the organic matter content in a Dystrophic Oxisol under no-tillage. The experiment was conducted in a randomized block design, in split plots, with four replications. The plots were composed by four systems of crop rotation and the subplots by four sampling depths $(0-10 ; 10-20$; 20-40, and 40-60 cm). The crops were: rice (R); irrigated dry bean (DB); corn (C); soybean (S); rice $(\mathrm{R}+\mathrm{B})$, corn $(\mathrm{C}+\mathrm{B})$, and soybean $(\mathrm{S}+\mathrm{B})$ intercropped with Brachiaria. The crop rotation systems were: S1 - R/DB/C/DB/S/DB; S2 - R+B/DB/C+B/DB/S+B/DB; S3 - C/DB/S/DB/S/DB; and $\mathrm{S} 4-\mathrm{C}+\mathrm{B} / \mathrm{DB} / \mathrm{S}+\mathrm{B} / \mathrm{DB} / \mathrm{S}+\mathrm{B} / \mathrm{DB}$. It was considered a native forest, located at $500 \mathrm{~m}$ from the experiment, as reference. The inclusion of Brachiaria in crop rotation systems did not affect soil bulk density, macroporosity, and available soil water capacity. Total soil porosity and organic matter content of the soil were favored in the crop rotations that included more number of soybean cultivations. The association of soybean with Brachiaria contributed to the stability of the aggregates and the summer grasses with Brachiaria to reduce the soil resistance to penetration.
\end{abstract}

KEYWORDS: soil bulk density, soil porosity, soil aggregation.

\footnotetext{
${ }^{1}$ Extraído da dissertação de Mestrado do primeiro autor.

${ }^{2}$ Eng ${ }^{\circ}$ Agrônomo, Doutorando em Agronomia, UFG - GO, euraimi@ yahoo.com.br

${ }^{3}$ Eng ${ }^{0}$ Agrônomo, Pesquisador A, Embrapa Arroz e Feijão, Caixa Postal 179, Santo Antonio de Goiás - GO, balbino@cnpaf.embrapa.br; stone@cnpaf.embrapa.br. Bolsista CNPq.

${ }^{4}$ Engo Agrônomo, Professor, Departamento de Agricultura, UFG - GO, leandro@agro.ufg.br. Bolsista do CNPq.

Recebido pelo Conselho Editorial em: 5-10-2005

Aprovado pelo Conselho Editorial em: 24-7-2007
} 


\section{INTRODUÇÃO}

A estrutura do solo agrícola é modificada em razão da compactação, o que pode promover, com alguma intensidade, a destruição de macroagregados, degradando sua estrutura, podendo dificultar o crescimento de raízes e, conseqüentemente, diminuir o volume explorado (TAVARES FILHO et al., 1999).

$\mathrm{O}$ uso de sistemas conservacionistas de manejo, com menor revolvimento de solo e que proporcionem acúmulo de resíduos culturais na superfície, possibilitam a recuperação das propriedades físicas do solo (ROS et al., 1997). Entretanto, o solo em plantio direto, após três ou quatro anos, pode apresentar maiores valores de densidade e microporosidade, e menores valores de macroporosidade e porosidade total, comparado ao preparo convencional, principalmente devido ao trânsito de máquinas e implementos agrícolas (STONE \& SILVEIRA, 2001). TORMENA \& ROLOFF (1996) quantificaram a resistência do solo à penetração em plantio direto e observaram que a presença de camadas compactadas em subsuperfície parece ter influenciado na resistência à penetração em profundidade e que o tráfego de máquinas demonstrou ser o fator mais importante na alteração da estrutura do solo em plantio direto. A compactação do solo em plantio direto aumenta a resistência do solo à penetração, sendo admitidos valores na ordem de 5,0 MPa (EHLERS et al., 1983), devido à continuidade dos poros, resultantes da decomposição das raízes, bem como à liberação do exsudatos radiculares e à atividade biológica do solo mais efetiva, proporcionando maior estabilidade dos agregados (TISDALL \& OADES, 1982).

As gramíneas perenes, por meio de seu sistema radicular, promovem efeito positivo na agregação e na estabilidade dos agregados do solo (SILVA \& MIELNICZUK, 1998). Uma das alternativas de inclusão de gramíneas perenes nos sistemas agrícolas, para melhorar as propriedades físicas do solo, produzir cobertura morta para o plantio direto e alimento para o gado na integração lavoura-pecuária, é o Sistema Santa Fé, desenvolvido pela Embrapa Arroz e Feijão (KLUTHCOUSKI et al., 2000). Esse sistema consiste no cultivo associado de culturas anuais, graníferas ou forrageiras, como milho, sorgo, milheto e arroz, com espécies forrageiras, principalmente as do gênero Brachiaria.

Este trabalho teve o objetivo de comprovar se a inclusão de braquiária na rotação de culturas, pela sua alta relação $\mathrm{C} / \mathrm{N}$, poderia melhorar as propriedades físico-hídricas e o conteúdo de matéria orgânica de um Latossolo Vermelho distrófico de textura muito argilosa em plantio direto.

\section{MATERIAL E MÉTODOS}

O estudo foi conduzido na área experimental da Embrapa Arroz e Feijão, em Santo Antônio de Goiás - GO. O solo é classificado como Latossolo Vermelho distrófico, com composição granulométrica de 614,$4 ; 77,8$ e $307,8 \mathrm{~g} \mathrm{~kg}^{-1}$ de solo, respectivamente, para argila, silte e areia.

O ensaio foi implantado a partir da safra 2000/2001, em sistema plantio direto, e as avaliações foram realizadas na entressafra de 2003. A área experimental encontrava-se em plantio direto desde a safra 1997/1998, com cultivo de milho no verão e de feijão irrigado no inverno.

As culturas utilizadas foram: arroz (A); feijão irrigado (F); milho (M); soja (S), e arroz $(\mathrm{A}+\mathrm{B})$, milho $(\mathrm{M}+\mathrm{B})$ e soja $(\mathrm{S}+\mathrm{B})$ consorciados com braquiária (Brachiaria brizantha, cv. Marandu). Os sistemas de rotação avaliados foram: S1 - A/F/M/F/S/F; S2 A+B/F/M+B/F/S+B/F; $\mathrm{S} 3-\mathrm{M} / \mathrm{F} / \mathrm{S} / \mathrm{F} / \mathrm{S} / \mathrm{F}$, e $\mathrm{S} 4-\mathrm{M}+\mathrm{B} / \mathrm{F} / \mathrm{S}+\mathrm{B} / \mathrm{F} / \mathrm{S}+\mathrm{B} / \mathrm{F}$. Foi considerada, como controle, mata nativa situada a $500 \mathrm{~m}$ do ensaio. As dimensões das parcelas foram de $8 \mathrm{~m}$ x $18 \mathrm{~m}\left(144 \mathrm{~m}^{2}\right)$, com corredores de $1 \mathrm{~m}$ entre elas.

A semeadura e a adubação das culturas foram realizadas sempre nos meses de novembro, na safra, e julho, na entressafra irrigada, por meio de semeadora-adubadora de plantio direto. A semeadura do feijão-solteiro, cultivar Radiante, no plantio de inverno de 2003, foi feita no dia 2-7-2003 sobre a palhada dessecada da cultura anterior ou da braquiária associada, no espaçamento de 0,45 m entre fileiras, com 15 a 17 sementes por metro. A adubação utilizada foi $500 \mathrm{~kg} \mathrm{ha}^{-1} \mathrm{da}$ 
fórmula 4-30-16 + 0,2\% $\mathrm{Zn}$ e duas adubações de cobertura, a primeira no dia 23-7-2003 e a segunda no dia 6-8-2003, ambas com $40 \mathrm{~kg} \mathrm{ha}^{-1}$ de N, na forma de sulfato de amônio. A cultura foi irrigada por aspersão, sistema pivô central, até a sua maturidade fisiológica.

No pleno florescimento do feijoeiro irrigado, em uma trincheira de $0,80 \mathrm{~m} \times 0,80 \mathrm{~m}$ por parcela, foram coletadas cinco amostras por profundidade $(0-10 ; 10-20 ; 20-40$ e 40-60 cm), sendo uma deformada e quatro não-deformadas (uma no formato de torrão e três pelo método do cilindro), as quais foram submetidas a análises físico-hídricas. As amostras com estrutura deformada foram utilizadas para determinar a textura do solo pelo método da pipeta, e a densidade de partículas (Dp), pelo método do balão volumétrico (EMBRAPA, 1997). Duas amostras nãodeformadas, coletadas em cilindros de $5 \mathrm{~cm}$ de diâmetro e $5 \mathrm{~cm}$ de altura, foram usadas para a determinação da densidade do solo (Ds) e da microporosidade. Essa foi considerada a quantidade de água retida pelo solo à tensão de $6 \mathrm{kPa}$, sendo utilizada para a determinação uma mesa de tensão. A porosidade total $(\mathrm{Pt})$ foi calculada pela equação: $\mathrm{Pt}=(1-\mathrm{Ds} / \mathrm{Dp})$.

A macroporosidade foi obtida pela diferença entre a porosidade total e a microporosidade (EMBRAPA, 1997). A outra amostra não-deformada foi usada para a determinação das curvas de retenção de água pelo método da centrífuga (FREITAS JÚNIOR \& SILVA, 1984), nas tensões de água de $0 ; 1 ; 3 ; 8 ; 10 ; 33 ; 60 ; 100$ e $1.500 \mathrm{kPa}$. As curvas características de água no solo foram ajustadas por meio de regressão não-linear, utilizando-se do modelo matemático proposto por GENUCHTEN (1980). Após o ajuste, calculou-se a capacidade de água disponível, como a diferença entre os conteúdos de umidade do solo nas tensões de $8 \mathrm{kPa}$ (capacidade de campo) e $1.500 \mathrm{kPa}$ (ponto de murcha permanente). A amostra indeformada obtida no formato de torrão foi utilizada para determinar a estabilidade de agregados em água pelo método descrito pela EMBRAPA (1997). Adotou-se como índice de agregação o diâmetro médio ponderado dos agregados (DMP).

Foi determinado, também, o teor de matéria orgânica do solo, nas profundidades de 0-5; 5-10; 10-20; 20-40 e 40-60 cm, pelo método de Walkley Black (EMBRAPA, 1997).

Determinou-se a resistência do solo à penetração por meio do penetrômetro de impacto modelo IAA/PLANALSULCAR-Stolf, na profundidade de 0-60 cm, em quatro pontos na entrelinha da cultura, sendo 16 observações por tratamento. Os dados de campo foram obtidos em número de impactos $\mathrm{dm}^{-1}(\mathrm{~N})$, tendo sido os valores transformados em resistência do solo à penetração $(\mathrm{R})$, por meio da equação: $\mathrm{R}\left(\mathrm{kgf} \mathrm{cm}^{-2}\right)=5,6+6,98 \mathrm{~N}$ (STOLF et al., 1983). Posteriormente, transformou-se a unidade para MPa. A umidade do solo foi determinada gravimetricamente em dois pontos por parcela, ao lado dos pontos de observação.

Os tratamentos foram distribuídos nas unidades experimentais, utilizando-se do delineamento de blocos ao acaso, com quatro repetições, no arranjo experimental em parcelas subdivididas. As parcelas foram constituídas pelas rotações de cultura, e as subparcelas, pelas profundidades de amostragem. A análise de variância dos dados, com exceção dos relativos à resistência do solo à penetração, foi realizada utilizando-se do procedimento GLM do programa estatístico SAS (SAS INSTITUTE, 1999), sendo as médias comparadas pelo teste de Tukey, a 5\% de probabilidade. As médias dos tratamentos foram comparadas com as obtidas no solo de mata nativa (controle), pelo teste de Dunnett, a 5\%. Foi realizada análise de regressão linear entre a variável DMP e o teor de matéria orgânica do solo, considerando todas as profundidades de amostragem.

\section{RESULTADOS E DISCUSSÃO}

A análise de variância (Tabela 1) indica que houve efeito significativo das rotações apenas na porosidade total e no teor de matéria orgânica do solo. A profundidade de amostragem, por sua vez, afetou significativamente todas as variáveis, com exceção da capacidade de água disponível. Não houve, entretanto, interação significativa entre esse tratamento e as rotações, para todas as variáveis analisadas. 
TABELA 1. Análise de variância das propriedades físico-hídricas e do teor de matéria orgânica em diferentes camadas de um Latossolo Vermelho distrófico, sob sistemas de rotação de culturas em plantio direto.

\begin{tabular}{lrrrcrcccc}
\hline \multicolumn{1}{c}{ Fonte de } & \multicolumn{7}{c}{ Valor de $\mathrm{F}^{(1)}$} \\
\cline { 2 - 10 } \multicolumn{1}{c}{ Variação } & \multicolumn{1}{c}{$\mathrm{Ds}{ }^{(2)}$} & $\mathrm{Pt}$ & $\mathrm{Mp}$ & $\mathrm{mp}$ & $\mathrm{DMP}$ & $\mathrm{CAD}$ & $\mathrm{CC}$ & $\mathrm{PMP}$ & M.O. \\
\hline Rotação (R) & $2,03 \mathrm{~ns}$ & $5,66^{* *}$ & $1,40 \mathrm{~ns}$ & $1,54 \mathrm{~ns}$ & $1,22 \mathrm{~ns}$ & $0,21 \mathrm{~ns}$ & $0,68 \mathrm{~ns}$ & $1,00 \mathrm{~ns}$ & $3,77^{*}$ \\
Profundidade(P) & $13,32^{* *}$ & $14,48^{* *}$ & $7,33^{* *}$ & $3,47^{*}$ & $25,98^{* *}$ & $0,16 \mathrm{~ns}$ & $3,53^{*}$ & $3,61^{*}$ & $119,70^{* *}$ \\
Interação R x P & $0,86 \mathrm{~ns}$ & $0,97 \mathrm{~ns}$ & $0,48 \mathrm{~ns}$ & $0,67 \mathrm{~ns}$ & $0,60 \mathrm{~ns}$ & $0,60 \mathrm{~ns}$ & $1,11 \mathrm{~ns}$ & $1,77 \mathrm{~ns}$ & $0,35 \mathrm{~ns}$ \\
\hline
\end{tabular}

${ }^{(1)}$ ns - não-significativo; **significativo a $1 \%$ de probabilidade; *significativo a $5 \%$ de probabilidade, pelo teste $\mathrm{F}$.

${ }^{(2)} \mathrm{Ds}$ - densidade do solo; $\mathrm{Pt}$ - porosidade total; Mp - macroporosidade; mp - microporosidade; DMP - diâmetro médio ponderado; CAD - capacidade de água disponível; CC - capacidade de campo; PMP - ponto de murcha permanente; M.O. - matéria orgânica.

O solo no sistema de rotação $\mathrm{S} 3$, que incluiu cultivos solteiros de milho e soja, mostrou tendência de apresentar menor valor de densidade do solo e maiores de macroporosidade e porosidade total, embora só tenha havido diferenças significativas entre os sistemas de rotação de culturas quanto a essa última propriedade (Tabela 2). Nesse sistema, o solo apresentou maior valor de porosidade total que o no sistema S2, que incluiu cultivos consorciados de arroz, milho e soja com braquiária. Provavelmente, a inclusão de maior número de cultivos de soja no sistema S3 tenha contribuído para acelerar a decomposição do material orgânico, pelo maior fornecimento de nitrogênio, melhorando as propriedades físicas do solo pelo maior aporte de carbono orgânico em relação ao sistema $\mathrm{S} 2$, que incluía material com alta relação $\mathrm{C} / \mathrm{N}$.

TABELA 2. Valores médios de densidade do solo, macroporosidade e porosidade total nas diferentes camadas de um Latossolo Vermelho distrófico, sob sistemas de rotação de culturas em plantio direto. ${ }^{(1)}$

\begin{tabular}{|c|c|c|c|c|c|c|}
\hline \multirow{2}{*}{$\begin{array}{c}\text { Camada } \\
(\mathrm{cm})\end{array}$} & \multicolumn{5}{|c|}{ Sistema de Rotação ${ }^{(2)}$} & \multirow{2}{*}{ Mata } \\
\hline & S1 & S2 & S3 & $\mathrm{S} 4$ & Média & \\
\hline & \multicolumn{5}{|c|}{ Densidade do Solo $\left(\mathrm{Mg} \mathrm{m}^{-3}\right)$} & \\
\hline $0-10$ & 1,24 & 1,27 & 1,16 & 1,21 & $1,22 b^{*}$ & 0,94 \\
\hline $10-20$ & 1,29 & 1,31 & 1,29 & 1,30 & $1,30 a^{*}$ & 1,06 \\
\hline $20-40$ & 1,26 & 1,34 & 1,29 & 1,30 & $1,30 a^{*}$ & 1,02 \\
\hline $40-60$ & 1,21 & 1,20 & 1,18 & 1,19 & $1,20 b^{*}$ & 1,00 \\
\hline Média & $1,25 \mathrm{~A}^{*}$ & $1,28 A^{*}$ & $1,23 A^{*}$ & $1,25 \mathrm{~A}^{*}$ & & 1,00 \\
\hline \multirow[t]{2}{*}{ C.V.(\%) } & \multicolumn{5}{|c|}{4,64} & \\
\hline & \multicolumn{5}{|c|}{ Macroporosidade $\left(\mathrm{m}^{3} \mathrm{~m}^{-3}\right)$} & \\
\hline $0-10$ & 0,162 & 0,156 & 0,217 & 0,197 & $0,183 a^{*}$ & 0,295 \\
\hline $10-20$ & 0,126 & 0,127 & 0,143 & 0,121 & $0,129 b^{*}$ & 0,276 \\
\hline $20-40$ & 0,104 & 0,109 & 0,139 & 0,115 & $0,117 b^{*}$ & 0,293 \\
\hline $40-60$ & 0,146 & 0,175 & 0,159 & 0,149 & $0,157 \mathrm{ab} *$ & 0,268 \\
\hline Média & $0,135 \mathrm{~A}^{*}$ & $0,142 A^{*}$ & $0,165 \mathrm{~A}^{*}$ & $0,146 A^{*}$ & & 0,283 \\
\hline \multirow[t]{2}{*}{ C.V. $(\%)$} & \multicolumn{5}{|c|}{29,62} & \\
\hline & \multicolumn{5}{|c|}{ Porosidade Total $\left(\mathrm{m}^{3} \mathrm{~m}^{-3}\right)$} & \\
\hline $0-10$ & 0,503 & 0,494 & 0,553 & 0,516 & $0,517 a^{*}$ & 0,618 \\
\hline $10-20$ & 0,482 & 0,451 & 0,490 & 0,485 & $0,477 b^{*}$ & 0,585 \\
\hline $20-40$ & 0,488 & 0,465 & 0,490 & 0,483 & $0,482 b^{*}$ & 0,598 \\
\hline $40-60$ & 0,511 & 0,515 & 0,525 & 0,521 & $0,518 \mathrm{a} *$ & 0,591 \\
\hline Média & $0,496 \mathrm{AB}^{*}$ & $0,481 \mathrm{~B}^{*}$ & $0,515 \mathrm{~A}^{*}$ & $0,501 \mathrm{AB}^{*}$ & & 0,598 \\
\hline C.V. $(\%)$ & \multicolumn{5}{|c|}{4,64} & \\
\hline
\end{tabular}

(1) Médias seguidas da mesma letra maiúscula na linha e minúscula na coluna não diferem entre si, a $5 \%$ de probabilidade, pelo teste de Tukey, e as seguidas por asterisco diferem significativamente da mata nativa (controle), pelo teste de Dunnett, a $5 \%$. (2) $\mathrm{S} 1$ - A/F/M/F/S/F; S2 - A+B/F/M+B/F/S+B/F; S3 - M/F/S/F/S/F; S4 $\mathrm{M}+\mathrm{B} / \mathrm{F} / \mathrm{S}+\mathrm{B} / \mathrm{F} / \mathrm{S}+\mathrm{B} / \mathrm{F}$; $\operatorname{arroz}(\mathrm{A})$; feijão irrigado $(\mathrm{F}) ;$ milho $(\mathrm{M})$; soja $(\mathrm{S})$; $\operatorname{arroz}(\mathrm{A}+\mathrm{B})$, milho $(\mathrm{M}+\mathrm{B})$ e soja (S+B) consorciados com braquiária. 
A variação dessas propriedades com a profundidade do solo provavelmente deve-se ao maior teor de matéria orgânica na camada superficial (Tabela 3), que atenuou os efeitos do nãorevolvimento do solo. Na camada de 40-60 cm de profundidade, esses efeitos não mais ocorrem.

TABELA 3. Valores médios de diâmetro médio ponderado dos agregados e conteúdo de matéria orgânica nas diferentes camadas de um Latossolo Vermelho distrófico, sob sistemas de rotação de culturas em plantio direto. ${ }^{(1)}$

\begin{tabular}{|c|c|c|c|c|c|c|}
\hline \multirow{2}{*}{$\begin{array}{l}\text { Camada } \\
(\mathrm{cm})\end{array}$} & \multicolumn{5}{|c|}{ Sistema de Rotacão ${ }^{(2)}$} & \multirow{2}{*}{ Mata } \\
\hline & S1 & $\mathrm{S} 2$ & S3 & S4 & Média & \\
\hline & \multicolumn{5}{|c|}{ Diâmetro Médio Ponderado (mm) } & \\
\hline $0-10$ & 4,19 & 4,14 & 3,91 & 4,32 & $4,14 a^{*}$ & 4,68 \\
\hline $10-20$ & 3,64 & 3,45 & 3,80 & 3,72 & $3,65 b^{*}$ & 4,69 \\
\hline $20-40$ & 3,44 & 2,86 & 3,25 & 3,28 & $3,21 \mathrm{bc} *$ & 4,75 \\
\hline $40-60$ & 2,89 & 2,92 & 2,72 & 3,09 & $2,91 c^{*}$ & 3,62 \\
\hline Média & $3,54 \mathrm{~A}^{*}$ & $3,34 A^{*}$ & $3,42 \mathrm{~A}^{*}$ & $3,60 A^{*}$ & & 4,44 \\
\hline \multirow[t]{2}{*}{ C.V.(\%) } & \multicolumn{5}{|c|}{12,19} & \\
\hline & \multicolumn{5}{|c|}{ Matéria Orgânica $\left(\mathrm{g} \mathrm{dm}^{-3}\right)$} & \\
\hline $0-5$ & 19,50 & 19,00 & 20,25 & 20,00 & $19,69 a^{*}$ & 25,00 \\
\hline $5-10$ & 17,25 & 17,00 & 18,25 & 18,67 & $17,79 b^{*}$ & 22,50 \\
\hline $10-20$ & 15,75 & 15,33 & 16,50 & 16,67 & $16,06 c^{*}$ & 20,00 \\
\hline $20-40$ & 13,50 & 12,67 & 14,25 & 15,00 & $13,86 \mathrm{~d}^{*}$ & 15,50 \\
\hline $40-60$ & 10,25 & 10,00 & 10,25 & 10,00 & $10,13 \mathrm{e}^{*}$ & 12,00 \\
\hline Média & $15,25 \mathrm{AB} *$ & $14,80 \mathrm{~B} *$ & $15,90 \mathrm{AB} *$ & $16,07 \mathrm{~A}^{*}$ & & 19,00 \\
\hline C.V. $(\%)$ & \multicolumn{5}{|c|}{8,72} & \\
\hline
\end{tabular}

${ }^{(1)}$ Médias seguidas da mesma letra maiúscula na linha e minúscula na coluna não diferem entre si, a $5 \%$ de probabilidade, pelo teste de Tukey, e as seguidas por asterisco diferem significativamente da mata nativa (controle), pelo teste de Dunnett, a $5 \%$. ${ }^{(2)} \mathrm{S} 1$ - A/F/M/F/S/F; S2 - A+B/F/M+B/F/S+B/F; S3 - M/F/S/F/S/F; S4 $\mathrm{M}+\mathrm{B} / \mathrm{F} / \mathrm{S}+\mathrm{B} / \mathrm{F} / \mathrm{S}+\mathrm{B} / \mathrm{F}$; $\operatorname{arroz}(\mathrm{A})$; feijão irrigado (F); milho (M); soja (S); arroz (A+B), milho (M+B) e soja (S+B) consorciados com braquiária.

Independentemente da profundidade e do sistema de rotação, o solo da mata apresentou os menores valores de densidade e os maiores valores de macroporosidade e porosidade total, corroborando os resultados de BERGAMIN et al. (2002). Esses autores relatam que a ausência da ação de máquinas e equipamentos, associada à elevada cobertura do solo e matéria orgânica na vegetação nativa, afeta de forma positiva as propriedades físicas do solo.

Os valores da densidade do solo variaram entre $0,94 \mathrm{Mg} \mathrm{m}^{-3}$, para a mata nativa, na camada superficial de 0-10 cm, a 1,34 $\mathrm{Mg} \mathrm{m}^{-3}$, para o sistema $\mathrm{S} 2$, na profundidade de 20-40 $\mathrm{cm}$ (Tabela 2). Esses valores foram inferiores a $1,40 \mathrm{Mg} \mathrm{m}^{-3}$ que, segundo ARSHAD et al. (1996), restringe o crescimento radicular em solo argiloso. Os valores encontrados neste estudo foram similares aos encontrados por HARRIS et al. (1996), os quais observaram, na profundidade de $30 \mathrm{~cm}$, que a densidade do solo apresentou valores de 1,07 e 1,31 $\mathrm{Mg} \mathrm{m}^{-3}$, respectivamente, para área preservada e de plantio direto. Segundo BALBINO (2001), os solos da região do Cerrado, com teores de argila superiores ou iguais a $700 \mathrm{~g} \mathrm{~kg}^{-1}$ de solo, apresentam densidades inferiores a $1,00 \mathrm{Mg} \mathrm{m}^{-3}$, sendo relativamente constante no perfil do solo sob vegetação natural. No entanto, os solos com teores de argila inferiores a esse valor apresentam densidades superiores e variáveis no perfil.

Verifica-se, na Tabela 1, que a microporosidade foi afetada pela profundidade de amostragem no nível de $5 \%$, enquanto a macroporosidade o foi a $1 \%$. Isso indica que a macroporosidade está mais sujeita a mudanças impostas pelo manejo do que a microporosidade, fato constatado por ALBUQUERQUE et al. (2001), demonstrando que o aumento da densidade e a redução dos macroporos, provavelmente, devem-se à compactação causada pelo trânsito de máquinas e implementos agrícolas utilizados no plantio da safra de verão, quando a umidade do solo é geralmente elevada. BALBINO (2001) afirma que, após o desmatamento, observa-se, via de regra, 
aumento da densidade do solo. A macroporosidade é a primeira a ser afetada por essas transformações, com evolução marcada nos horizontes superficiais do solo.

Os sistemas de rotação de culturas não diferiram quanto ao seu efeito no diâmetro médio ponderado dos agregados do solo (Tabela 3). A adoção de sistemas de culturas e manejos que mantenham a proteção do solo e o contínuo aporte de resíduos orgânicos, é fundamental para a manutenção da sua boa estrutura (LAL \& GREENLAND, 1979). ELTZ et al. (1989) observaram que o plantio direto proporcionou maior tamanho de agregados estáveis em água, comparado com o sistema convencional de preparo de solo, possivelmente devido à não-destruição mecânica dos agregados pelos implementos de preparo do solo e à proteção que a palha oferece à superfície do solo.

Mesmo com a adoção do plantio direto e a inclusão de espécies de alta relação $\mathrm{C} / \mathrm{N}$, os sistemas de rotação avaliados ainda não foram capazes de promover o mesmo estado de agregação que a mata nativa (Tabela 3), talvez devido ao seu pouco tempo de implantação (três anos), que não foi suficiente para elevar o conteúdo de matéria orgânica do solo no nível da mata nativa. Entretanto, o sistema S4, que incluiu mais vezes a consorciação soja e braquiária, apresentou tendência de promover melhor agregação do solo, possivelmente pelo aumento do conteúdo de matéria orgânica do solo devido à contribuição dos resíduos da leguminosa com o nitrogênio, aumentando a taxa de decomposição da palhada da gramínea. BEUTLER et al. (2001), em um Latossolo Vermelho distrófico, textura muito argilosa, fase cerrado, também verificaram que a matéria orgânica favoreceu a agregação do solo.

O efeito positivo da matéria orgânica na agregação do solo pode ser visualizado na Figura 1. Isso ocorre pelo fato de ela ser o principal agente da estabilização dos agregados do solo (TISDALL \& OADES, 1982).

Os sistemas que incluem a combinação de pastagens perenes de gramíneas e leguminosas além de culturas anuais, são os mais eficientes na manutenção de uma boa estrutura. As pastagens perenes atuam por períodos mais prolongados, onde as gramíneas apresentam renovação, e os resíduos das leguminosas contribuem com o nitrogênio e aumentam a taxa de decomposição pela baixa relação $\mathrm{C} / \mathrm{N}$.

Como o conteúdo de matéria orgânica diminuiu com a profundidade devido a que, no plantio direto, o aporte de matéria seca se concentra na superfície do solo, o diâmetro médio ponderado dos agregados também diminuiu com o incremento da profundidade do solo (Tabela 3).

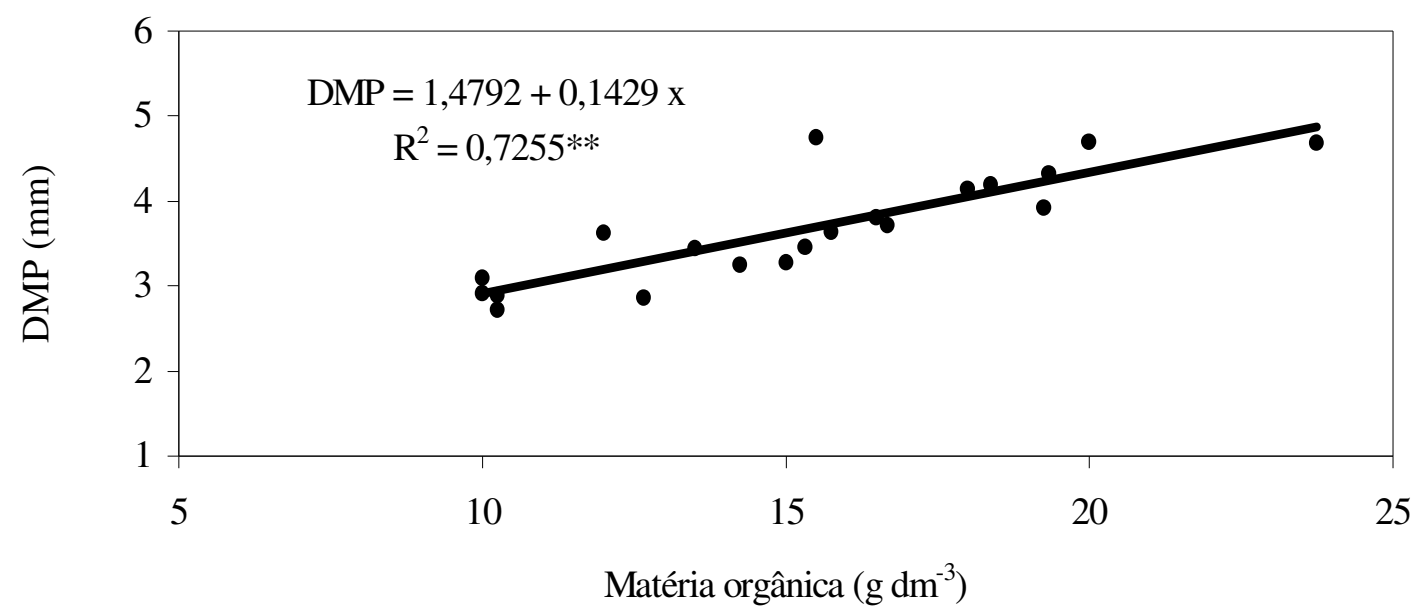

FIGURA 1. Correlação entre diâmetro médio ponderado dos agregados (DMP) e matéria orgânica em Latossolo Vermelho distrófico em plantio direto. 
Os valores de resistência à penetração refletiram a influência dos sistemas de manejo no arranjo das unidades estruturais ao longo do perfil (Figura 2). Houve variação de 0,55 MPa para todos os tratamentos, independentemente da umidade do solo, na profundidade inicial de $0-2 \mathrm{~cm} \mathrm{e}$ $3,18 \mathrm{MPa}$, para o sistema $\mathrm{S} 3$, na profundidade de $35 \mathrm{~cm}$, com umidade de $0,32 \mathrm{~cm}^{3} \mathrm{~cm}^{-3} \mathrm{e}$, para a área com mata nativa, a maior resistência do solo à penetração foi de $3,37 \mathrm{MPa}$, na profundidade de $24 \mathrm{~cm}$ e umidade de $0,21 \mathrm{~cm}^{3} \mathrm{~cm}^{-3}$, valores que, segundo ARSHAD et al. (1996), estão compreendidos entre as classes baixa e alta.

As menores resistências à penetração na camada superficial $(0-10 \mathrm{~cm})$ foram consequiência do não-revolvimento da camada do solo nessa profundidade em plantio direto e pelo seu maior aporte de matéria orgânica, contribuindo para a maior agregação do solo. Na profundidade 35-60 $\mathrm{cm}$, não houve diferença entre os tratamentos, provavelmente devido à pouca influência que o manejo do solo possui nessa camada, apesar de o solo apresentar menor umidade na mesma.

O sistema de rotação $\mathrm{S} 2$ que, além da braquiária, incluiu as gramíneas arroz e milho, apresentou menores valores de resistência à penetração (2,30 a 2,71 MPa), na profundidade de 15$35 \mathrm{~cm}$, proporcionando melhores condições para o desenvolvimento radicular em relação ao $\mathrm{S} 1$, cuja única diferença daquele foi a ausência da braquiária no sistema e menor umidade do solo (Figura 2). Nota-se que, no tratamento mata nativa, nessa profundidade, a resistência à penetração foi maior que nos sistemas de rotação, variando de 2,93 a 3,28 MPa. Tal fato relaciona-se à maior umidade nos sistemas de rotação, pois o feijoeiro, na estação seca, foi irrigado durante todo o ciclo, demonstrando que o fator umidade possui relação direta com a resistência do solo à penetração. Os valores elevados de resistência à penetração na camada de $10-35 \mathrm{~cm}$, nos sistemas de rotação, não chegam a comprometer as culturas instaladas, devido à maior continuidade de poros, homogeneidade do solo e à maior atividade microbiana que normalmente ocorrem no plantio direto (ARSHAD et al., 1996). EHLERS et al. (1983) relatam que valores de resistência à penetração na ordem de 5,0 MPa são admitidos em plantio direto, pois as raízes crescem por canais contínuos deixados pela fauna do solo e pelo sistema radicular decomposto.
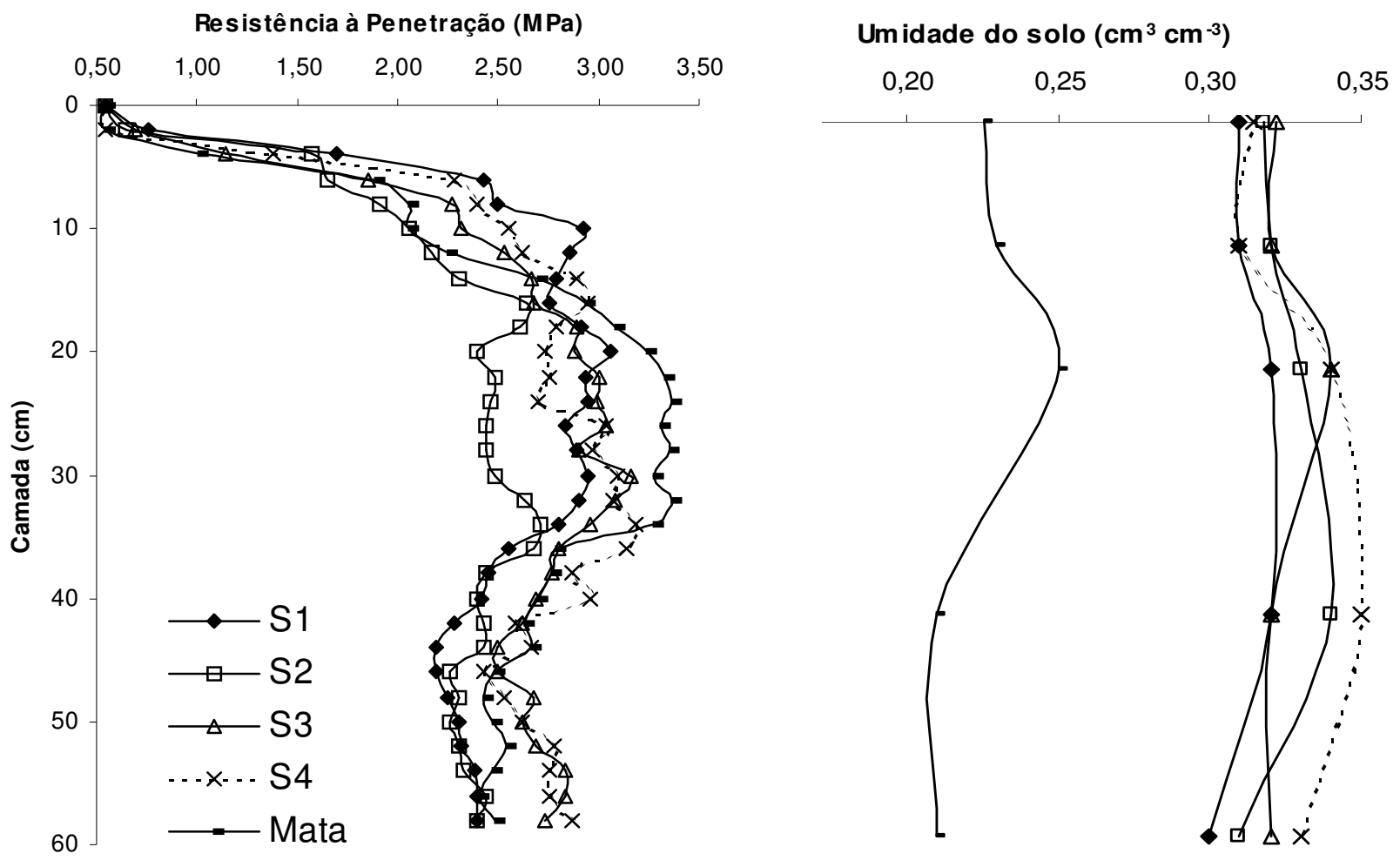

FIGURA 2. Resistência do solo à penetração sob sistemas de rotação de culturas em plantio direto, com a respectiva umidade do solo. $\mathrm{S} 1$ - A/F/M/F/S/F; S2 - A+B/F/M+B/F/S+B/F; S3 $\mathrm{M} / \mathrm{F} / \mathrm{S} / \mathrm{F} / \mathrm{S} / \mathrm{F} ; \mathrm{S} 4$ - M+B/F/S+B/F/S+B/F; Arroz (A); feijão irrigado (F); milho (M); soja $(\mathrm{S})$; arroz $(\mathrm{A}+\mathrm{B})$, milho $(\mathrm{M}+\mathrm{B})$ e soja $(\mathrm{S}+\mathrm{B})$ consorciados com braquiária. 
Os sistemas de rotação de culturas não diferiram quanto à capacidade de água disponível do solo, umidade na capacidade de campo e no ponto de murcha permanente (Tabela 4). Isso provavelmente foi devido à semelhança entre as rotações com relação ao seu efeito na densidade do solo. Essa mesma propriedade do solo explica as diferenças em profundidade na umidade, na capacidade de campo e no ponto de murcha permanente. O solo da mata, por apresentar menores valores de densidade, apresentou menores valores dessas propriedades em relação às rotações estudadas, em todas as profundidades, com exceção de 10-20 cm. Nessa profundidade, o solo da mata apresenta o seu maior valor de densidade.

TABELA 4. Valores médios da capacidade de água disponível do solo, capacidade de campo e ponto de murcha permanente, em diversas camadas de um Latossolo Vermelho distrófico, sob sistemas de rotação de culturas em plantio direto. ${ }^{(1)}$

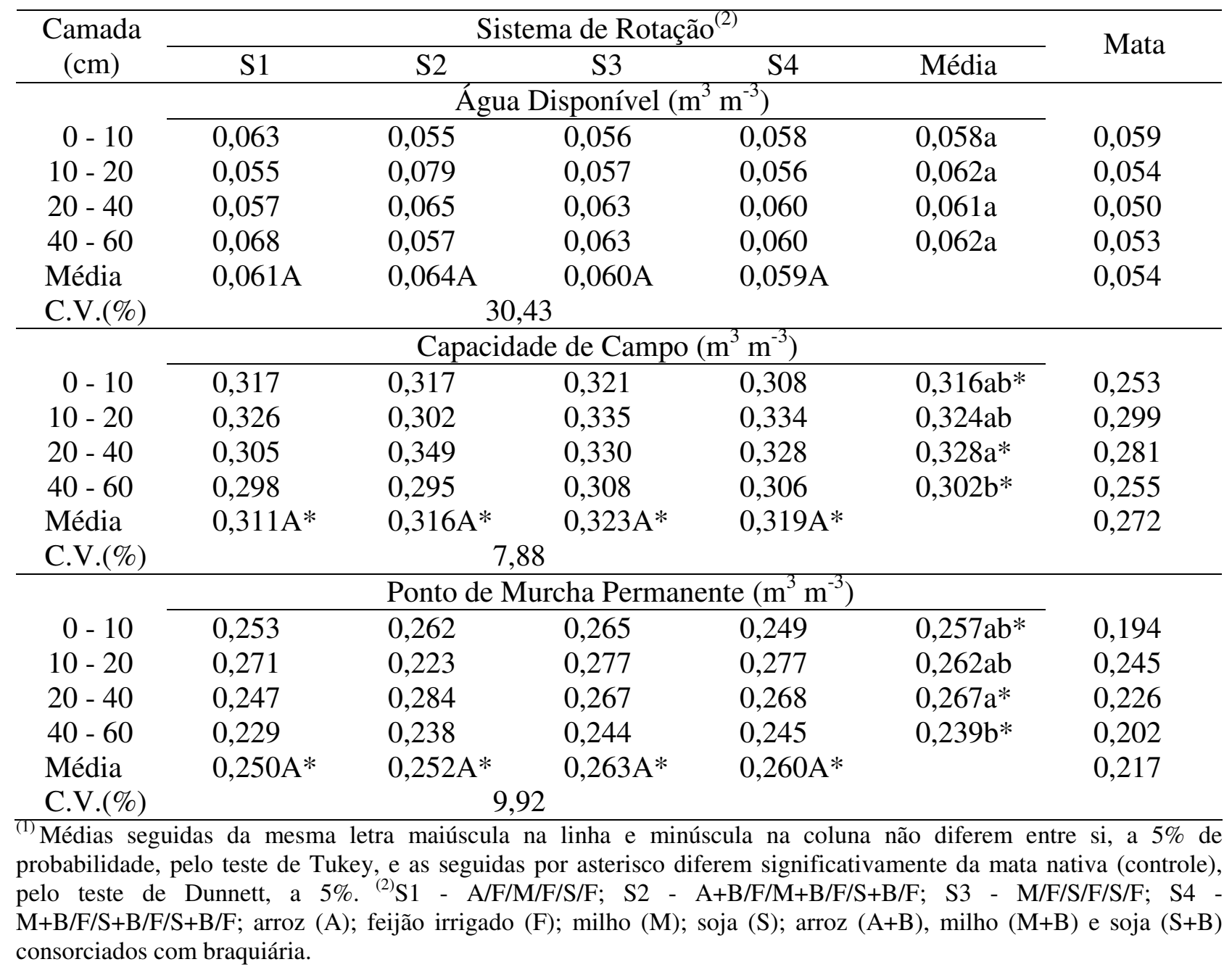

\section{CONCLUSÕES}

A inclusão da braquiária na rotação de culturas não afetou a densidade, a macroporosidade e a capacidade de água disponível do solo.

A porosidade total e o teor de matéria orgânica do solo foram favorecidos pelas rotações que incluíram maior número de cultivos de soja.

A associação de soja com a braquiária contribuiu para a estabilidade dos agregados.

A associação de gramíneas de verão com a braquiária contribuiu para diminuir a resistência do solo à penetração. 


\section{REFERÊNCIAS}

ALBUQUERQUE, J.A.; SANGOL, L.; ENDER, M. Efeitos da integração lavoura-pecuária nas propriedades físicas do solo e características da cultura do milho. Revista Brasileira de Ciência do Solo, Viçosa, v.25, n.3, p.717-23, 2001.

ARSHAD, M.A.; LOWERY, B.; GROSSMAN, B. Physical tests for monitoring soil quality. In: DORAN, J.W.; JONES, A.J. (Eds.). Methods for assessing soil quality. Madison: Science Society of America, 1996. p.123-41. (SSSA, Special Publication, 49).

BALBINO, L.C. Évolution de la structure et des propriétés hydrauliques dans des Ferralsols mis en prairie Pâturée (Cerrado, Brésil). 2001. 128 f. Thèse (Doctora) - INA-PG, Paris, 2001.

BERGAMIN, E.M.; FENDT, F.O.; SILVA, A.P. de; CIDIN, A.C.M.; TOMIYOSH JÚNIOR, E.M.; ABREU, S.L. de; SAMPAIO, F.A.R.; SILVA, R.J.S. da. Alterações causadas pela pastagem e sistema agroflorestal na densidade do solo e porosidade total em Argissolo Vermelho distrófico na Amazônia. In: REUNIÃO BRASILEIRA DE MANEJO E CONSERVAÇÃO DO SOLO E DA ÁGUA, 14., 2002, Cuiabá. Anais... Cuiabá: Universidade Federal de Cuiabá, 2002. 1 CD-ROM.

BEUTLER, A.N.; SILVA, M.L.N.; CURI, N.; FERREIRA, M.M.; PEREIRA FILHO, I.A.; CRUZ, J.C. Agregação de Latossolo Vermelho distrófico típico relacionada com o manejo na região dos Cerrados no Estado de Minas Gerais. Revista Brasileira de Ciência do Solo, Viçosa, v.25, n.1, p.129-36, 2001.

EHLERS, W.; KOPKE, V.; HESSE, F.; BOHM, W. Penetration resistance and root growth of oats in tilled and untilled loess soil. Soil Tillage Research, Amsterdam, v.3, n.2, p.261-75, 1983.

ELTZ, F.L.F.; PEIXOTO, R.T.G.; JASTER, F. Efeitos de sistemas de preparo de solo nas propriedades físicas e químicas de um Latossolo Bruno álico. Revista Brasileira de Ciência do Solo, Campinas, v.13, n.2, p.259-67, 1989.

EMBRAPA. EMPRESA BRASILEIRA DE PESQUISA AGROPECUÁRIA. Serviço Nacional de Levantamento e Conservação de Solos. Manual de métodos de análise de solos. 2.ed. Rio de Janeiro, 1997. 212 p.

FREITAS JÚNIOR, E.; SILVA, E.M. Uso da centrífuga para a determinação da curva de retenção de água no solo, em uma única operação. Pesquisa Agropecuária Brasileira, Brasília, v.19, n.11, p.1423-8, 1984.

GENUCHTEN, M.T. Van. A closed form equation for predicting the hydraulic properties of unsaturated soils. Soil Science Society of America Journal, Madison, v.44, n.5, p.892-8, 1980.

HARRIS, R.F.; KARLEN, D.L.; MULLA, D.J.A. A conceptual framework for assessment and management of soil quality and health. In: DORAN, J.W.; JONES, A.J. (Eds.). Methods for assessing soil quality. Madison: Soil Science Society of America, 1996. p.61-82. (SSSA, Special Publication, 49).

KLUTHCOUSKI, J.; COBUCCI, T.; AIDAR, H.; YOKOYAMA, L.P.; OLIVEIRA, I.P. de; COSTA, J.L.S.; VILELA, L.; BARCELLOS, A.O.; MAGNABOSCO, C.U. Sistema Santa Fé tecnologia Embrapa: integração lavoura-pecuária pelo consórcio de culturas anuais com forrageiras, em áreas de lavoura, nos sistemas direto e convencional. Santo Antônio de Goiás: Embrapa Arroz e Feijão. 2000. 28 p. (Circular Técnica, 38).

LAL, R.; GREENLAND, B.J. Soil physical properties and crop production in tropics. Winchester: John Willey, 1979. $85 \mathrm{p}$.

ROS, C.O. da; SECCO, D.; FIORIN, J.E.; PETRERE, C.; CADORE, M.A.; PASA, L. Manejo do solo a partir de campo nativo: efeito sobre a forma e estabilidade da estrutura ao final de cinco anos. Revista Brasileira de Ciência do Solo, Campinas, v.21, n.2, p.241-7, 1997.

SAS Institute Inc. SAS/STAT procedure guide for personal computers: version 5. Cary, NC, 1999. 
SILVA, I.R.; MIELNICZUK, J. Sistemas de cultivo e características do solo afetando a estabilidade de agregados. Revista Brasileira de Ciência do Solo, Viçosa, v.22, n.2, p.311-17, 1998.

STOLF, R.; FERNANDES, J.; FURLANI NETO, V.L. Penetrômetro de impacto, IAA/Planalsucar-Stolf: recomendações para o seu uso. STAB, Piracicaba, v.1, n.3, p.18-23, 1983.

STONE, L.F.; SILVEIRA, P.M. da. Efeitos do sistema de preparo e da rotação de culturas na porosidade e densidade do solo. Revista Brasileira de Ciência do Solo, Viçosa, v.25, n.2, p.395401, 2001.

TAVARES FILHO, J.; RALISCH, R.; GUIMARÃES, M.F.; MEDINA, C.C.; BALBINO, L.C.; NEVES, C.S.V.J. Método do perfil cultural para avaliação do estado físico de solos em condições tropicais. Revista Brasileira de Ciência do Solo, Viçosa, v.23, n.2, p.393-9, 1999.

TISDALL, J.M.; OADES, J.M. Organic matter and water-stable aggregates in soils. Journal of Soil Science, Oxford, v.33, p.141-63, 1982.

TORMENA, C.A. dos; ROLOFF, C.A. Dinâmica da resistência à penetração de um solo sob plantio direto. Revista Brasileira de Ciência do Solo, Campinas, v.20, n.2, p.333-9, 1996. 